\title{
Speculations on the Role of Transmissible Agents in the Pathogenesis of Alzheimer's Disease
}

\author{
Ashley T. Haase, Elizabeth Lewis, Stephen Wietgrefe, Mary Zupancic, \\ Jane Diedrich, Hal Minnigan, and Melvyn J. Ball
}

\begin{abstract}
Unconventional agents and conventional viruses provide model systems to investigate the pathogenesis of Alzheimer's disease (AD). The essay which follows examines the hypothetical role of herpes simplex in AD and presents some generally applicable experimental approaches to detecting genes in brain tissues. The concluding section, on parallels between $A D$ and diseases of the brain caused by unconventional viruses, defines strategies for isolating genes related to pathology.
\end{abstract}

RÉSUMÉ: Spéculation sur le rôle des agents transmissibles dans la pathogénèse de la maladie d'Alzheimer. Les agents non-conventionnels et les virus conventionnels fournissent des système modèles pour l'investigation de la pathogénèse de la maladie d'Alzheimer (MA). Nous analysons dans cet article le rôle hypothétique du virus de l'herpès simplex dans la MA et nous présentons des approches expérimentales d'application générale pour détecter les gènes dans le tissu cérébral. La conclusion qui traite des parallèles entre la MA et les maladies du cerveau causées par des virus non-conventionnels élabore des stratégies pour isoler des gènes qui sont en rapport avec un état pathologique.

Can. J. Neurol. Sci. 1986; 13:449-451

There is no evidence that Alzheimer's disease (AD) is itself transmissible' but transmissible agents nonetheless provide good models to study the pathogenesis of degenerative diseases like $\mathrm{AD}$, and some conventional viruses, like herpes simplex virus (HSV), may have a direct role in the pathogenesis of AD. This short essay is an extended speculation on these two themes, accompanied by a brief review of some of the technical gambits which may be of general use to neuropathologists.

\section{The Virus Hypothesis}

Ball ${ }^{2}$ has advanced the hypothesis that reactivation of HSV in the brain in critical regions (limbic system) for associative memory ${ }^{3,4}$ causes AD. He bases his hypothesis on several observations: 1) the high proportion of human trigeminal ganglia with HSV and evidence of recurring inflammation consistent with reactivation; 2) plausible anatomic routes for the spread of HSV from the ganglion to the temporal lobe and limbic system structures which show the most extensive pathological involvement in AD; 3) documented centripetal spread and establishment of latent infection in the brains of animals infected with HSV; $;^{5-7}$ and 4 ) reports of detection of HSV DNA in human brain. ${ }^{10,11}$

\section{Hybridization Tests of the Virus Hypothesis}

The strong prediction of the virus hypothesis is the presence of the HSV genome in the appropriate anatomic locations. This can be tested by in situ hybridization, a technique which localizes viral or other sequences in single cells in tissue sections $;{ }^{12,13}$ and by macroscopic-microscopic hybridization, ${ }^{14}$ a method which combines in situ hybridization with large-scale screening of sections to enhance the sampling power of the technique. These methods currently can detect the equivalent of $0.02 \mathrm{HSV}$ genomes per cell in tissue sections fixed in formalin to preserve cellular morphology. ${ }^{15,16}$ Because these techniques detect viral DNA in the relatively rare latently infected cell, they are considerably more sensitive than methods which depend on nucleic acids extracted from the whole tissue where viral sequences may be diluted beyond the limits of detection. This dilution effect may be responsible for the negative results obtained thus far for $\mathrm{HSV}$ in $\mathrm{AD} .{ }^{17}$ We have undertaken a survey of ganglionic and brain tissues in collaboration with Dr. Ball to evaluate the proposed spread of HSV to the human brain and the relationship of this event to the pathological changes in AD. As a first step we have optimized the hybridization procedures and demonstrated that we can detect HSV DNA in the sensory neurons

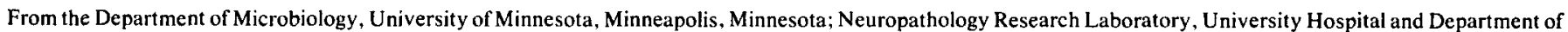
Pathology, University of Western Ontario, London, Ontario (Dr. Ball)

Reprint requests to: Ashley T. Haase, Department of Microbiology, University of Minnesota, Minneapolis, MN U.S.A. 55455 
in the trigeminal ganglion of man (Figure 1). With this encouraging result in hand, we have begun the examination of brain tissues from $\mathrm{AD}$ patients and controls.

\section{Unconventional Agents and the Pathogenesis of AD}

Unconventional scrapie and other virus-like agents can cause pathological alterations analogous to those seen in AD. We reasoned that these parallels, such as the formation of neuritic plaques, might reflect activation of the same set of genes. Thus, cloning of genes of this type might shed some light on the basis for the tissue lesions. We looked for genes whose expression increases in scrapie and AD by cloning DNA copies of mRNAs obtained from the brains of infected animals. We screened this

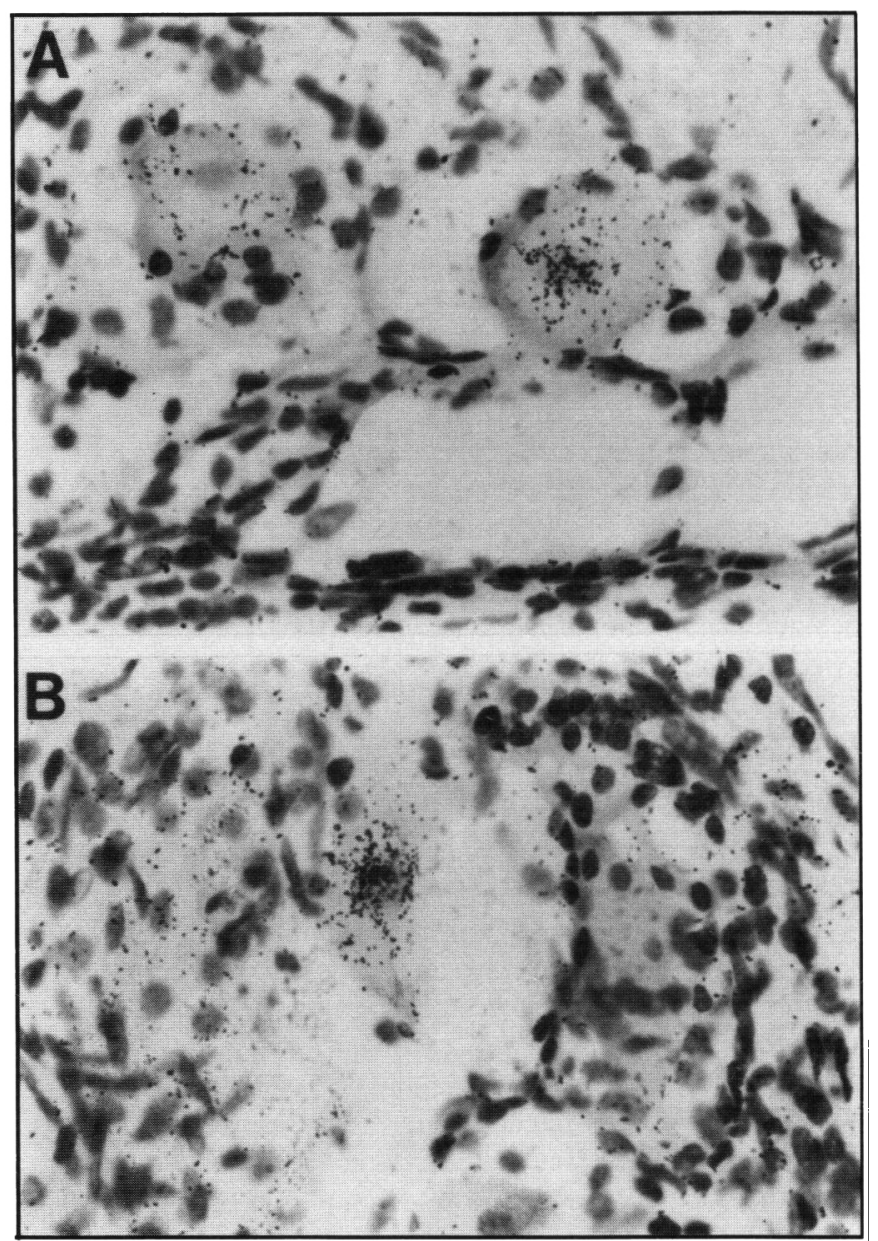

Figure 1 - Detection of herpes simplex virus DNA in human trigeminal ganglia. The trigeminal ganglion of a 75 year old patient who died of pneumonia after aortobifemoral bypass was removed 19 hours postmortem. fixed overnight in freshly prepared $4 \%$ paraformaldehyde, and transferred to $70 \%$ alcohol. The specimen was embedded in paraffin and the sections were cut and picked up on treated glass slides. This and all subsequent procedures for in situ hybridization followed protocols described in detail in references 12,13 . The HSV probe ${ }^{19}$ consists of EcoRI and HindIII clones representing all parts of the genome but devoid of sequences which hybridize to sequences in normal human DNA. ${ }^{20.21}$ The sequence complexity of this collection is equivalent to about $45 \%$ of the $150 \mathrm{~Kb}$ genome. The probe was labelled by nick translation with ${ }^{125} \mathrm{I}$ and ${ }^{35} \mathrm{~S}$ to a specific activity of $10^{9} \mathrm{dpm}$ per $\mu \mathrm{g}$. Radioautographic exposure was 5 days. Stained with hematoxylin and eosin, original magnification $X 400$. The large sensory neurons in $A$ and $B$ have a significant increase in silver grains clustered over the nucleus. Dark staining inflammatory cells are adjacent to the latently infected neurons in $A$ and surround the positive cell in $B$. library with probes copied from mRNAs of infected and uninfected animals to identify clones which gave a higher signal with the scrapie probe indicating a greater abundance of a particular mRNA in the infected brain. The first such clone, Scr-1, identified by differential screening, turns out to be a single copy gene whose expression increases about twenty-fold in scrapie infection. By in situ hybridization Scr-1 mRNA is increased in a focal pattern particularly prominent in areas adjacent to the ventricles of infected animals. The increased binding in $\mathrm{AL}$ of Scr-1 is confined to neuritic plaques, largely in cellular processes. The precise nature of this transcript is under investigation, but from the sequence of the clone we know that the 3' untranslated portion of Scr-1 mRNA is closely related to glial fibrillary acidic protein.

\section{Prospectus}

The underlying premise of the investigations of scrapie and $\mathrm{AD}$ is the concept that degenerative, infectious, or other kinds of pathological developments reflect dysregulation of gene

\section{Pathology and Aberrant Gene Expression}

Construct CONA library

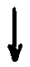

Differential screen + pathological state

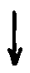

Ident ify genes whose expression increases or decreases

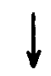

Algorithm to define "interesting" genes

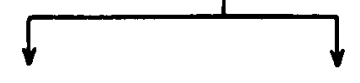

Sequence

in situ hybridization

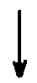

Homologous to known protein

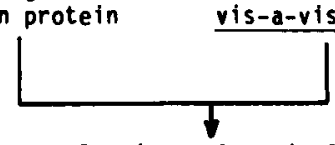

Further evaluation: Genomic localization and structure, expression during development

Figure 2 - Rationale and general strategy to clone and identify pathology related genes in $A D$. Pathological changes in $A D$ are hypothesized to be the result of an increase or decrease in gene expression which bears a plausible spatial and temporal relationship to the tissue lesions or loss of function. To identify these genes a $c D N A$ library is constructed from the mRNAs extracted from the brains of patients with $A D$. This library is screened differentially with probes from $A D$ and controls to detect clones which give an enhanced or diminished signal as a result of the increase or decrease of abundance of the respective mRNAs. Their relevance to the pathological state is then assessed by sequencing and hybridization to see if they are brain specific and localized in cells and anatomic regions which could account for the particular tissue change or loss of function. Clones which meet these criteria of "interest" are then evaluated further as to genomic localization (e.g., to chromosome 21 , because of the greatly increased incidence of $A D$ in Down's syndrome). 
expression. Identifying those genes whose expression increases or decreases in pathological conditions should therefore prove to be a general approach to the analysis of these conditions. We hope that this analysis, and the experimental strategy which supports it summarized in Figure 2, will provide insight and reagents for prevention, diagnosis and treatment of $\mathrm{AD}$ and other degenerative diseases.

\section{ACKNOWLEDGEMENTS}

Work in the senior author's laboratory has been supported by the National Institutes of Health, American Cancer Society, National Multiple Sclerosis Society, the Veterans Administration and the University of Minnesota. We thank Richard Hyman for the HSV DNAs and Sue Bonafield for preparation of the manuscript.

\section{REFERENCES}

1. Gibbs CJ, Gajdusek DC. Subacute spongiform virus encephalopathies: the transmissible virus dementias In: Katzman R, Terry RD, Bick KL, eds. Alzheimer's Disease: Senile Dementia and Related Disorders. New York: Raven Press, 1978: 559-575.

2. Ball MJ. Limbic predilection in Alzheimer dementia: is reactivated herpes virus involved? Canadian J Neurol Sci 1982; 9: 303-306.

3. Ball MJ, Hachinski V. Fox A, et al. A new definition of Alzheimer's disease: a hippocampal dementia. Lancet 1985; Jan 5: 14-16.

4. Hyman BT, Van Hoesen GW, Damasio AR, et al. Alzheimer's disease: cell-specific pathology isolates the hippocampal formation. Science 1984; 225: 1168-1170.

5. Puga A, Rosenthal JD, Openshaw $\mathrm{H}$, et al. Herpes simplex virus DNA and mRNA sequences in acutely and chronically infected trigeminal ganglia of mice. Virol 1978; 89: 102-111.

6. Cabrera $\mathrm{CV}$, Wohlenberg $\mathrm{C}$, Openshaw $\mathrm{H}$, et al. Herpes simplex virus DNA sequences in the CNS of latently infected mice. Nature 1980; 288: 288-290.

7. Stroop WG, Rock DL, Fraser NW. Localization of herpes simplex virus in the trigeminal and olfactory systems of the mouse central nervous system during acute and latent infections by in situ hybridization. Lab Invest 1984; 51: 27-38.
8. Efstathiou S, Minson A, Field HJ, et al. Detection of herpes simplex virus specific DNA sequences in latently infected mice and in humans. J Virol 1986; 57: 446-454.

9. McFarland DJ, Skiora E, Hotchin J. The production of focal herpes encephalitis in mice by stereotaxic inoculation of virus: anatomical and behavioral effects. J Neurol Sci 1986; 72:307-318.

10. Sequiera LW, Carrasco LH, Curry A, et al. Detection of herpessimplex viral genome in brain tissue. Lancet 1979; Sept 22:609-612.

11. Fraser NW, Lawrence WC, Wrobelwska Z, et al. Herpes simplex type I DNA in human brain tissue. Proc Natl Acad Sci USA 1981; 78: 6461-6465.

12. Haase AT, Brahic M, Stowring L, et al. Detection of viral nucleic acids by in situ hybridization. Meth Virol 1984; 8: 189-226.

13. Haase AT. Analysis of viral infections by in situ hybridization $/ n: \ln$ Situ Hybridization: Applications to Neurobiology symposium monograph. Fair Lawn, NJ: Oxford University Press (in press).

14. Haase AT, Gantz D, Blum $\mathrm{H}$, et al. Combined macroscopic and microscopic detection of viral genes in tissues. Virol 1985: 140: 201-206.

15. Haase AT, Gantz D, Eble B, et al. Natural history of restricted synthesis and expression of measles virus genes in subacute sclerosing panencephalitis. Proc Natl Acad Sci USA 1985: 82: $3020-3024$.

16. Blum HE, Haase AT, Vyas GN. Molecular pathogenesis of hepatitis $B$ virus infection: simultaneous detection of viral DNA and antigens in paraffin-embedded liver sections. Lancet 1984; Oct 6: $771-776$.

17. Taylor GR, Crow TJ, Markakis DA, et al. Herpes simplex virus and Alzheimer's disease: a search for virus DNA by spo hybridization. J Neurol Neurosurg Psychiatry.

18. Wietgrefe $S$, Zupancic $M$, Haase A, et al. Cloning of a gene whose expression is increased in scrapie and in senile plaques in human brain. Science 1985; 230: 1177-1179.

19. Jones TR, Hyman RW. Specious hybridization between herpes simplex virus DNA and human cellular DNA. Virol 1983; 131: $555-560$

20. Puga A, Cantin EM, Notkins AL. Homology between murine and human cellular DNA sequences and the terminal repetition of the $\mathrm{S}$ component of herpes simplex virus Type I DNA. Cell 1982; 31: 81-87.

21. Peden K, Mounts P, Hayward GS. Homology between mammalian cell DNA sequences and human herpes virus genomes detected by a hybridization procedure with high-complexity probe. Cell 1982; 31: $71-80$. 